\title{
Modern Stents: Where Are We Going?
}

\author{
Ofer Kobo, M.D., M.H.A. ${ }^{1}$, Majdi Saada, M.D. ${ }^{1}$, Simcha R. Meisel, M.D. ${ }^{1,2}$, Elias \\ Hellou, M.D., ${ }^{1,2}$ Aaron Frimerman, M.D. ${ }^{1,2}$, Rami Abu Fanne, M.D. ${ }^{1,2}$, Jameel \\ Mohsen, M.D. ${ }^{1}$, Asaf Danon, M.D. ${ }^{1,2}$, and Ariel Roguin, M.D., Ph.D. ${ }^{1,2}{ }^{*}$ \\ ${ }^{\prime}$ Department of Cardiology, Hillel Yaffe Medical Center, Hadera, Israel; and ' ${ }^{2}$ The Ruth E' Bruce \\ Rappaport Faculty of Medicine, Technion-Israel Institute of Technology, Haifa, Israel
}

\begin{abstract}
Coronary artery stenting is the treatment of choice for patients requiring coronary angioplasty. We describe the major advancements with this technology. There have been significant developments in the design of stents and adjunctive medical therapies. Newer-generation drug-eluting stents (DES) have almost negligible restenosis rates and, when combined with proper anti-platelet treatment and optimal deployment, a low risk of stent thrombosis. The introduction of newer-generation DES with thinner stent struts, novel durable or biodegradable polymer coatings, and new antiproliferative agents has further improved the safety profile of early-generation DES. In parallel the effectiveness has been kept, with a significant reduction in the risk of target lesion revascularization compared with the early-generation DES. However, to date, the development of completely bioresorbable vascular scaffolds has failed to achieve further clinical benefits and has been associated with increased thrombosis. Newer-generation DES-including both durable polymer as well as biodegradable polymer-have become the standard of care in all patient and lesion subsets, with excellent long-term results.
\end{abstract}

KEY WORDS: Bare metal stent, drug-eluting stents, history, percutaneous coronary intervention

\footnotetext{
Abbreviations: BMS, bare metal stent; BVS, bioresorbable vascular stents/scaffolds; DES, drug-eluting stents; MACE, main adverse cardiovascular events; OCT, optical coherence tomography; PCI, percutaneous coronary intervention.

Citation: Kobo O, Saada M, Meisel SR, Hellou E, Frimerman A, Fanne RA, Mohsen J, Danon A, Roguin A. Modern Stents: Where Are We Going? Rambam Maimonides Med J 2020;11 (2):eo017. Review. doi:10.5041/RMMJ.10403

Copyright: (C) 2020 Kobo et al. This is an open-access article. All its content, except where otherwise noted, is distributed under the terms of the Creative Commons Attribution License (http://creativecommons.org/licenses/by/3.0), which permits unrestricted use, distribution, and reproduction in any medium, provided the original work is properly cited.

Conflict of interest: No potential conflict of interest relevant to this article was reported.

* To whom correspondence should be addressed. E-mail: aroguin@technion.ac.il
} 


\section{INTRODUCTION}

Cardiovascular diseases, and specifically ischemic heart disease, are among the leading causes of morbidity and mortality worldwide. ${ }^{1}$ Percutaneous coronary intervention (PCI) revolutionized the treatment of coronary artery disease, and it is nowadays the most common method of coronary revascularization. ${ }^{2}$

The first balloon angioplasty in the coronary arteries was performed in 1977 by Dr Andreas R. Gruentzig in Zurich, Switzerland. This angioplasty procedure utilized an expandable balloon, fashioned on a kitchen table in Gruentzig's apartment. The efficacy of balloon angioplasty was limited by acute closure of the coronary artery in $5 \%$ to $10 \%$ of patients and high rates of restenosis, which occurred in as many as half of all revascularizations within the first year. Restenosis occurred by both elastic recoil and subsequent proliferation of smooth muscle cells at the site of endothelial damage caused by balloon inflations. ${ }^{3-5}$

Coronary stents were introduced in 1986 as an innovative solution and breakthrough for the acute recoil and vessel closure. The first stents were implanted by Puel in Toulouse and Sigwart in Zurich. Named the WALLSTENT, they were a stainless steel wire-mesh structure, self-expanding after deployment, and manufactured by Schneider AG (Bulach, Switzerland). At first, stents had high metallic density, resulting in a high incidence of subacute stent thrombosis. They were bulky and technically challenging to use, resulting in frequent failure in deployment and embolization. 6,7

It took several years to make stent implantation safe by refining the adjusted pharmacology and improving technical aspects of the procedure. Only in 1994 were the first coronary stents approved by the US Food and Drug Administration (FDA). Dr
Julio Palmaz, a radiologist, designed a balloonexpandable stainless-steel slotted metal tube, instead of a spring or coil. By trying different designs and types of metal, Dr Palmaz together with Dr Richard Schatz, a cardiologist, ultimately developed the Palmaz-Schatz stent. The stent was designed to provide a scaffold that would increase the acute gain in lumen diameter compared with percutaneous transluminal coronary balloon angioplasty alone and, thereby, reduce the rate of clinically relevant restenosis following PCI. The first FDA-approved stent had a mesh form built from stainless steel 163L and was relatively bulky.8,9

Since the Palmaz-Schatz stent, PCI has consistently evolved over time with the introduction of new and improved devices, techniques, and adjunctive pharmacotherapy.

\section{BARE-METAL STENTS}

The first stents were metal stents and were initially used as a bailout strategy for complication during balloon angioplasty. ${ }^{10}$ Most of the stents were made from stainless steel and were balloon-expandable. They were mounted on a balloon and were deployed by balloon inflation. Some were self-expandable and made from nitinol, a thermal shape memory alloy composed of nickel and titanium. After the introduction of the drug-eluting stent (DES) in the early 2000s, the first stents became known as bare metal stents (BMS).

The superiority of BMS over balloon angioplasty was shown in several randomized controlled trials, and elective stenting became a feasible clinical option. ${ }^{11,12}$ The technology of BMS improved in order to increase flexibility, "pushability," and radial strength. Better metal alloys were introduced (Table 1), as well as improved geometrical structures and

Table 1. Composition of Stent Alloys (Weight Percentage).

\begin{tabular}{l|c|c|c|c|c|c|c|c|c|}
\hline Material & Fe & Co & Cr & Pt & Ni & W & Mo & Mn & Ti \\
\hline 316L SS & 63 & & 18 & & 14 & & 2.6 & $<2.0$ & \\
CoCr (L605) & 3 & 50.5 & 20 & & 10 & 15 & & 1.5 & \\
PtCr & 37 & & 18 & 33 & 9 & & 2.6 & & \\
Nitinol & & & & & 55 & & & & 45 \\
\hline
\end{tabular}

Co, cobalt; $\mathrm{Cr}$, chromium; Fe, iron; $\mathrm{Mn}$, manganese; Mo, molybdenum; $\mathrm{Ni}$, nickel; Pt, platinum; SS, stainless steel; Ti, titanium; W, tungsten. 
better delivery systems (Figure 1). These improvements led to increased use of BMS over time. However, despite all improvements, BMS still resulted in early and late stent adverse events. ${ }^{14}$ The main challenge of BMS was high in-stent restenosis rates due to neointimal hyperplasia, which occurred in 10\%$30 \%$ of all stents. Predictors for stent failure included clinical factors, such as diabetes, and procedural and angiographic factors, such as treatment of bifurcation lesions, longer stents, small-caliber stents, stents that were not well opposed to the vessel wall, and lack of intracoronary imaging. Intravascular ultrasound initially was critical to understanding that stents were not properly being deployed, and its use identified the need for high-pressure inflations. This subsequently allowed the shift to antiplatelet agents and enabled patients to be discharged either the next day or, now, the same day. Prior to this observation patients had to be anticoagulated, which required prolonged hospitalization. Some authors suggested that routine use of intravascular imaging may result in better long-term outcomes. ${ }^{8}$

Many different strategies tried to address the issue of restenosis, for example heparin-coating of the stents or endothelial-seeded stents. Intracoronary beta and gamma radiation was also used for a brief period, but it caused endothelial damage and reduced ability for local tissue healing. This tech- nology was almost completely abandoned, and is still being used in only few centers worldwide.

Among the many solutions was the idea that antiproliferative drugs could be delivered locally via a polymer release mechanism in high enough concentrations to reduce neointimal hyperplasia but at a slow enough rate to avoid systemic toxicity. It was this insight that allowed the development of DES.

\section{DRUG-ELUTING STENTS}

First approved in the early 2000s, DES shared the stainless-steel backbone of BMS. However, they had new components: an immunosuppressant or cytotoxic drug to inhibit neointimal hyperplasia and a polymer to which that drug was fixed. The purpose of the polymer was to serve as a diffusion barrier that allowed the prolonged release of the antineoplastic agent. ${ }^{15}$ Use of DES had significantly improved clinical outcomes as compared with BMS, primarily through a notable reduction in the rates of repeat revascularization.

The first generation of DES released sirolimus and paclitaxel over the course a month, resulting in a significant reduction in the need for revascularization compared with BMS. ${ }^{16,17}$ The number needed to treat to prevent repeat revascularization was between
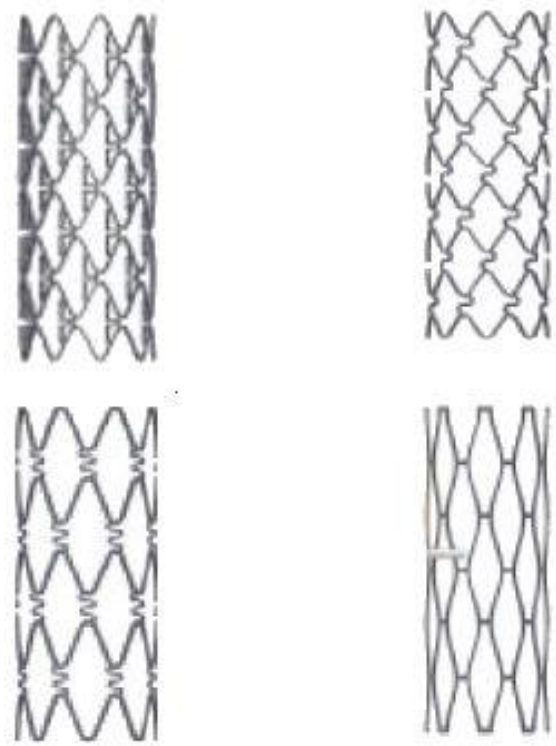
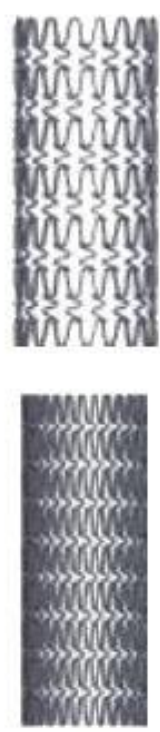
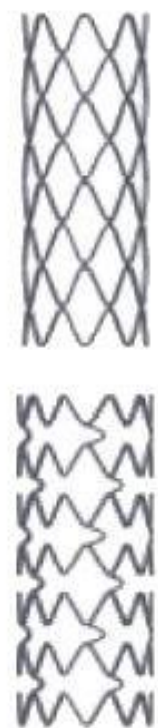

Figure 1. Stent Structures. Several examples of the different geometrical stent structures in the early years of stents. Adapted from Figure 3 of Paisal et al. ${ }^{13}$ [CC by 3.0]. 
6 and 10, according to a large meta-analysis. Firstgeneration DES soon became the mainstay of PCI. However, it was suggested in 2006 that DES may carry an increased non-negligible risk for late stent thrombosis, compared to BMS. ${ }^{18,19}$ Extensive analyses failed to confirm this concern, but safety improvements were studied and implemented. The potent anti-restenosis effect of early-generation DES came at the expense of delayed arterial healing of the stented coronary segment, characterized by chronic inflammation at the stented site with uncovered stent struts, coronary evaginations and positive vessel remodeling, fibrin deposition, and neoatherosclerosis. ${ }^{20}$ This pathological process has been proposed as a mechanism of the risk of late thrombotic events-specifically very late stent thrombosis after implantation of the early-generation Cypher sirolimus-eluting stent and Taxus paclitaxel-eluting stent.

In order to improve DES performance, and to achieve the ideal characteristics of flexibility, trackability, radial strength, and biocompatibility, constant efforts were invested in improvement of all the components-the platform, polymer, and drug. Second-generation DES have an improved platform with thinner strut thickness, allowing faster healing and endothelialization of the coronaries, and less inflammation and injury to the media as well. The platform was made of cobalt-chromium instead of stainless steel to make it more flexible and deliverable. Additionally, fluorinated polymers were developed that were more biocompatible and had thrombo-resistant properties. The eluted drugs in the second-generation DES were also changed, with the use of rapamycin derivatives with improved safety profile. Different DES designs are shown in Figure 2. Studies found that the duration of the dual antiplatelet therapy (DAPT) was very important in preventing stent thrombosis, especially for firstgeneration DES. ${ }^{22,23}$

A large randomized controlled trial (RCT) comparing second-generation DES and BMS found, over 6 years of follow-up, reduced risk of repeat revascularization and definite stent thrombosis, with the use of DES. It should be noted, however, that no improvement in mortality was proven. ${ }^{24}$ A pooled, patient-level analysis of four RCTs comparing second- and first-generation DES over a follow-up period of 2 years found significant reduction in the rates of stent thrombosis, with a concomitant reduction in cardiac death or myocardial infarction (MI) ${ }^{22}$; these results were confirmed in a further metaanalysis. ${ }^{23}$

Even with contemporary DES, and despite the significant reduction in thrombotic events, late stent failure is a concern. ${ }^{20,25,26}$ Some mechanisms were suggested to cause late stent failure, including hypersensitivity reaction, stent fracture, and in-stent neoatherosclerosis. Unlike atherosclerosis in native coronary arteries which develops over decades, instent neoatherosclerosis is a rapid process that may occur in months to years following stent placement. ${ }^{27}$ The incidence of neoatherosclerosis is similar after first- and second-generation DES implantation. ${ }^{20}$ Other potential causes for DES failure may be polymer-related. During stent implantation, polymers are at risk of bonding, webbing, cracking, or peeling. This may provide a thrombogenic nidus and decrease the uniformity of drug delivery, which may lead to stent thrombosis or restenosis. ${ }^{28}$ Recent developments target these mechanisms, with the aim to reduce and eliminate the long-term stent failure; new developments include polymer-free stents, bioresorbable polymer (BP) DES, and fully bioresorbable stents-commonly known as bioresorbable scaffolds.

\section{POLYMER-FREE DES}

The development of polymer-free DES was aimed at preventing adverse events caused by hypersensitivity reactions to polymer. Another potential problem these stents meant to solve is the cracking of the polymer coating while the stent is being inflated in the coronary artery. As the polymer purpose is to modify and control drug release, the challenge of polymer-free DES is to adequately control drug dose and elution kinetics in the early period after stent implantation. This required modification of the stent structure or the drug used. One suggested solution is a drug-filled stent (DFS) designed to provide controlled drug elution from an internal stent lumen without a polymer coating. In early trials the DFS showed encouraging clinical outcomes, minimal neointimal hyperplasia, and a high degree of stent strut coverage at 1 month post implantation optical coherence tomography (OCT). ${ }^{29}$ The use of a lipophilic rapamycin analogue, biolimus A9, in a polymer-free DES showed clinical benefits in patients at high risk of bleeding. ${ }^{30}$

A meta-analysis of 16 RCTs, with a total of over 15,000 patients, was recently published, comparing 


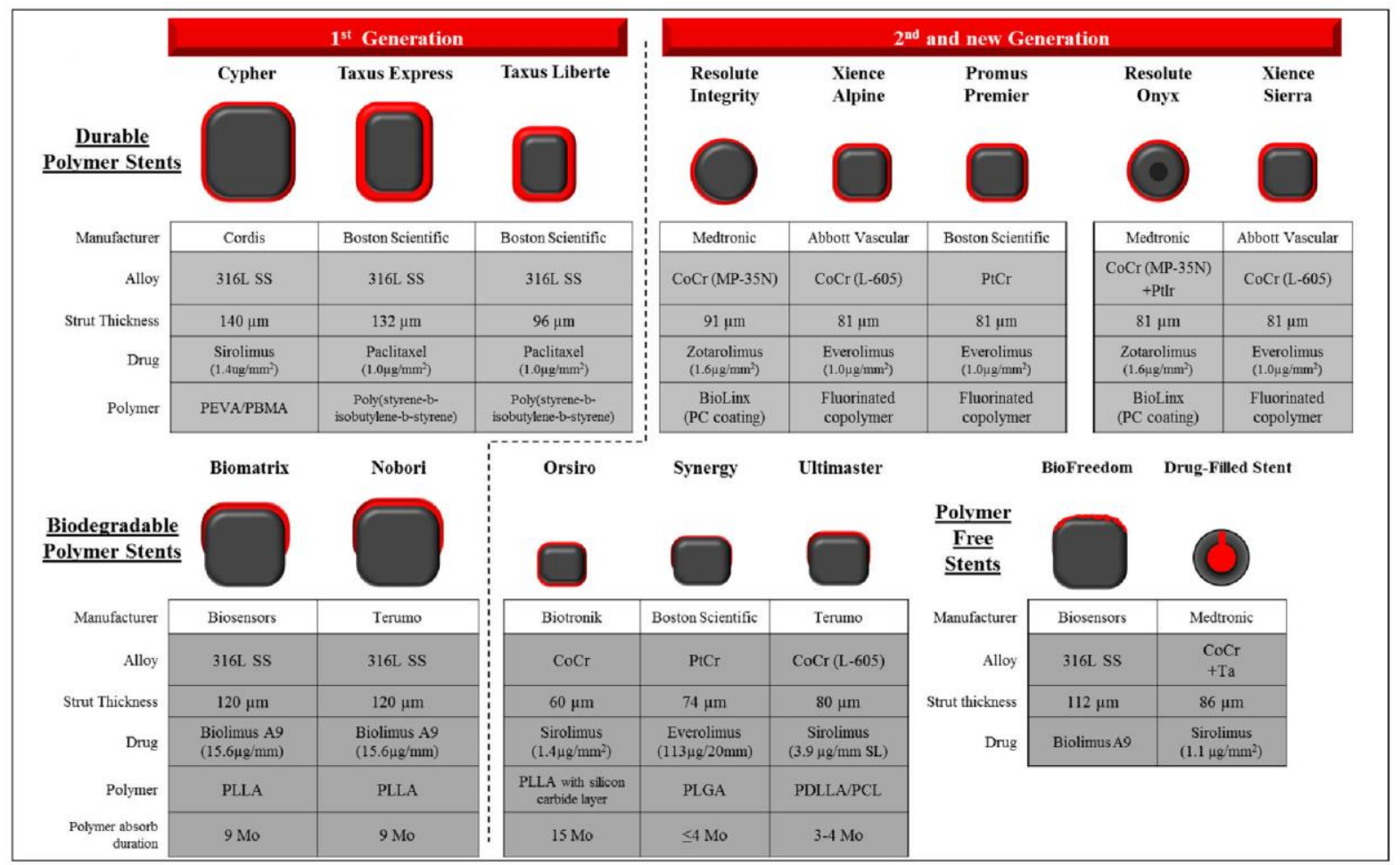

Figure 2. Different DES Designs.

Design characteristics (cross-sectional cut) of representative drug-eluting stents and bioabsorbable scaffold/stents. The characteristics of past and current commercial drug-eluting stents including durable polymer (DP)-, biodegradable polymer (BP)-, and polymer free-DES. Types of materials (alloy, drug, and polymer), strut thickness, and estimated duration of polymer absorption (in BP-DES) for each stent are described. CoCr, cobalt chromium; Ir, iridium; Mo, months; PBMA, poly(butyl methacrylate); PC, phosphorylcholine-coated; PCL, poly- $\varepsilon$-caprolactone; PDLA, poly-d-lactic acid; PDLGA, poly(d,l-lactide-co-glycolide); PDLLA, poly-d,l-lactic acid; PEVA, poly (ethylenevinyl acetate); PGA, polyglycolic acid; PLGA, poly(lactide-co-glycolide); PLLA, poly-l-lactic acid; Pt, platinum; SS, stainless steel.

polymer-free and polymer-coated DES. Polymer-free DES were associated to a significant $18 \%$ reduction in total mortality (OR 0.82 , 95\% CI $0.68-0.99$ ); however, no significant difference in main adverse cardiovascular events (MACE) was noted. An adequate subgroup analysis was not performed due to lack of data. ${ }^{31}$

\section{BIORESORBABLE POLYMER DES}

The hypothesis that led to of the development of bioabsorbable polymer was that chronic inflammatory responses to the polymer enhances late DES failure. Therefore, once the polymer dissolves, the stimulus for chronic inflammation will be eliminated. The biodegradable polymer matrix is composed of either polylactic or polylactic-co-glycolic acid. These polymers are converted to carbon dioxide and water, typically between 6 weeks and 24 months, depending on polymer configuration. Several large-scale studies proved the safety of the bioresorbable polymer (BP) DES and its non-inferiority over contemporary DES. ${ }^{22,33}$ A large meta-analysis including over 80,000 patients compared the biodegradable polymer biolimus-eluting stent to durable polymer drug-eluting and bare-metal stents, and found BP-DES to have a worse safety profile compared to contemporary DES. 34 However, a more contemporary meta-analysis, including several BPDES, found BP-DES to have similar safety and efficacy profiles to second-generation durable polymer DES. 35

An ultrathin-strut, bioabsorbable-polymer, sirolimus-eluting stent (OrSiro, Biotronik, Bulach, Switzerland) showed clinical benefit over secondgeneration DES, mainly in acute coronary syndrome, ${ }^{36,37}$ and its superiority in ST elevation myo- 
cardial infarction patients was also concluded from a large real-life PCI registry. ${ }^{38}$ Whether this suggested benefit is a BP-DES class effect or is secondary to the ultrathin struts formation is yet to be proven.

\section{BIORESORBABLE VASCULAR SCAFFOLDS}

What if the implanted stent would open the narrowing, keep the artery open for the period needed to heal, and then disappear? This is the logic behind the fully bioresorbable stents or scaffolds.

In-stent neoatherosclerosis occurs in BMS as well as in first- and second-generation DES. ${ }^{20}$ The development of fully bioresorbable vascular stents or scaffolds (BVS) aimed to reduce the incidence of this phenomenon. Other potential benefits of BVS include restoration of vasomotor function of the stented segment, elimination of the possibility of late stent fracture, improving side branch survival, and reducing the limitation of subsequent surgical revascularization of the stented segment. Some patients may also prefer avoiding a foreign body, if given the choice. 39 The BVS consists of synthetic biodegradable polymers that are intended to initially provide the benefits of DES and then dissolve within months after implantation. However, in order to provide the mechanical benefits of DES, thicker stent struts are always the prerequisite for BVS.

The first RCT comparing BVS to contemporary DES, the ABSORB III trial, demonstrated the everolimus-eluting poly-l-lactic acid-based Absorb bioresorbable vascular scaffold (BVS) to be noninferior to everolimus-eluting stents. 40 However, despite the positive outcomes, at 3-year follow-up, BVS were associated with significantly higher incidence of stent thrombosis and target-vessel MI. ${ }^{41}$ Further disappointing results for the BVS derived from the AIDA RCT. The trial data and safety monitoring recommended early reporting, which revealed significantly higher definite or probable device thrombosis with bioresorbable scaffolds (HR 3.87, 95\% CI 1.78-8.42).42

The hypothesis of improved vascular healing process with the use of BVS was also questioned. A trial using OCT for 6- and 12-month follow-up after implantation of BVS and DES found BVS to have a lower rate of uncovered and/or non-apposed struts; however, evaginations and discontinuities in device was more frequent with BVS. 43
Recently, the 5-year follow up of the ABSORB III trial was published, with a landmark analysis after 3 years (time of device absorption). The period of excess risk for BVS ended at 3 years, coincident with complete scaffold resorption. 44 It was also suggested that improved implantation technique may improve the clinical outcomes of the BVS45; nonetheless, in view of the current clinical data, BVS are not recommended for clinical use outside the setting of clinical studies. 46

Newer BVS technologies and devices are currently undergoing clinical and preclinical testing. One of the more promising BVS is a magnesium-based resorbable scaffold. Compared to previously used polymer, magnesium alloys possess somewhat better mechanical properties and biocompatibility as stent materials. 47 Imaging studies of the device revealed benign healing process at the edges of the BVS at 12-month follow-up. ${ }^{48}$ However, to date, the clinical data on this device are limited.

Pooled analysis of 184 patients and 189 lesions from the BIOSOLVE II and BIOSOLVE III trials revealed favorable efficacy and safety profiles during up to 12 months of follow-up, with no definite or probable scaffold thrombosis observed.49 Further clinical trials of the magnesium-based BVS with larger cohorts and longer follow-up are ongoing.

While the clinical evidence for the magnesiumbased BVS is appealing, further development of zincbased BVS has been carried out. Preliminary studies demonstrated that a tailored zinc-based material could be a promising candidate for a better stent material in the future. 47 Currently, although some scaffolds have the CE mark and are sold in Europe, most clinicians use them only in the setting of clinical studies. 46

\section{DRUG-COATED BALLOONS}

Another technology is to apply the anti-proliferative drug medication (usually paclitaxel) to a balloon. The medication is attached to the balloon using several different coating methods. Using a prolonged 60-second inflation, mainly in sites of restenosis, the medication is delivered locally to the tissue. The results of treating restenosis are similar to implanting a second layer of DES. Ample research is being performed to understand the place of drug-coated balloons in the treatment de novo lesions, mainly in small-caliber vessels. ${ }^{\circ}$ Currently the price of drug- 
coated balloons is much higher than DES, and their use is limited.

\section{CONCLUSIONS}

Coronary artery stenting is the treatment of choice for patients requiring coronary angioplasty. There have been significant developments in the design of BMS platforms, leading to reduction in restenosis. However, the newer-generation DES have almost negligible restenosis rates and, when combined with DAPT and optimal deployment, a low risk of stent thrombosis. The introduction of newer-generation DES with thinner stent struts, novel durable or biodegradable polymer coatings, and new antiproliferative agents has further improved the safety profile of early-generation DES. In parallel, the effectiveness was kept, with a significant reduction in the risk of target lesion revascularization compared with the early-generation DES. Accordingly, newergeneration DES-including both durable polymer and biodegradable polymer-have become the standard of care in all patient and lesion subsets, with excellent long-term results. The development of BVS, however, has failed to achieve further clinical benefits and is associated with increased thrombosis (Figure 3).
There are a number of ongoing studies to evaluate newer stent platforms, anti-proliferative drugs, novel polymers, polymer-free stents, and bioresorbable stents. It may be challenging for any new stent design or material to demonstrate better effectiveness and still be worth the cost of innovation. Interventional cardiologists have in their arsenal a wide variety of stents available with excellent performance. The quest for the ideal stent continues, but it will take a very large study in order to achieve this and prove device superiority.

\section{REFERENCES}

1. Roth GA, Johnson C, Abajobir A, et al. Global, regional, and national burden of cardiovascular diseases for 10 causes, 1990 to 2015. J Am Coll Cardiol 2017;70:1-25. CrossRef

2. Benjamin EJ, Blaha MJ, Chiuve SE, et al. Heart Disease and Stroke Statistics' 2017 Update: a report from the American Heart Association. Circulation 2017;135:e146-603. CrossRef

3. Gruntzig A. Transluminal dilatation of coronaryartery stenosis. Lancet 1978;1:263. CrossRef

4. Meier B. His master's art, Andreas Grüntzig's approach to performing and teaching coronary angioplasty. EuroIntervention 2017;13:15-27. CrossRef

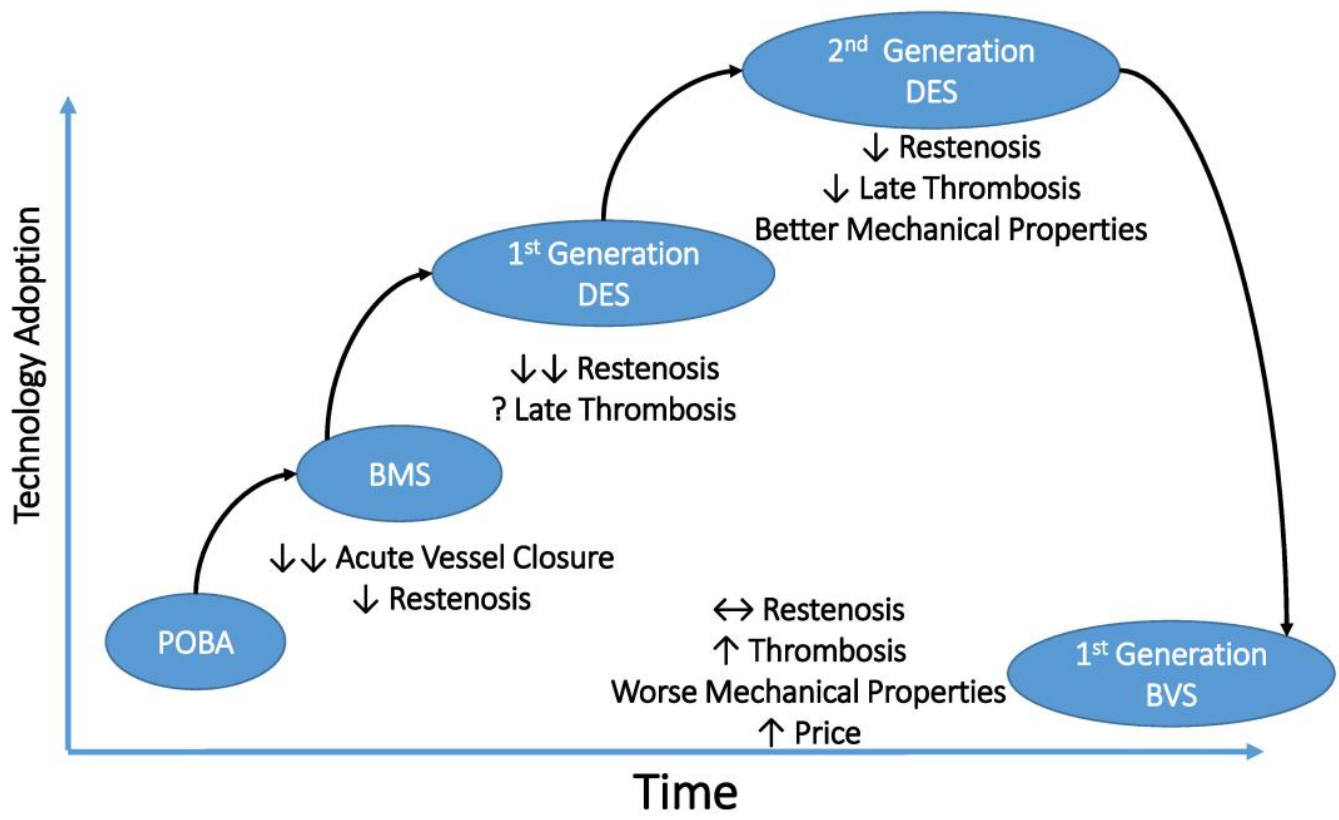

Figure 3. Evolution of Coronary Stents.

BMS, bare metal stent; BVS, bioresorbable vascular scaffolds; DES, drug-eluting stent; POBA, plain balloon angioplasty; $\leftrightarrow$, balanced; $\uparrow$, increased; $\downarrow$, decreased; $\downarrow \downarrow$, greatly decreased. 
5. Agostoni P, Valgimigli M, Biondi-Zoccai GG, et al. Clinical effectiveness of bare-metal stenting compared with balloon angioplasty in total coronary occlusions: insights from a systematic overview of randomized trials in light of the drug-eluting stent era. Am Heart J 2006;151:682-9. CrossRef

6. Serruys PW, Strauss BH, Beatt KJ, et al. Angiographic follow-up after placement of a selfexpanding coronary-artery stent. N Engl J Med 1991;324:13-17. CrossRef

7. Cantor WJ, Lazzam C, Cohen EA, et al. Failed coronary stent deployment. Am Heart J 1998; 136:1088-95. $\underline{\text { CrossRef }}$

8. Iqbal J, Gunn J, Serruys PW. Coronary stents: historical development, current status and future directions. Br Med Bull 2013;106:193-211. $\underline{\text { CrossRef }}$

9. Roguin A. Stent: the man and word behind the coronary metal prosthesis. Circ Cardiovasc Interv 2011; 4:206-9. CrossRef

10. Serruys PW, Keane D. The bailout stent. Is a friend in need always a friend indeed? Circulation 1993;88: 2455-7. CrossRef

11. Fischman DL, Leon MB, Baim DS, et al. A randomized comparison of coronary-stent placement and balloon angioplasty in the treatment of coronary artery disease. N Engl J Med 1994;331:496-501. CrossRef

12. Topol EJ. Caveats about elective coronary stenting. $\mathrm{N}$ Engl J Med 1994;331:539-41. $\underline{\text { CrossRef }}$

13. Paisal MSA, Taib I, Ismail AE. Computational analysis on stent geometries in carotid artery: a review. IOP Conf Ser Mater Sci Eng 2017:165;012003. CrossRef

14. Hearn JA, King SB 3rd, Douglas JS Jr, Carlin SF, Lembo NJ, Ghazzal ZM. Clinical and angiographic outcomes after coronary artery stenting for acute or threatened closure after percutaneous transluminal coronary angioplasty. Initial results with a balloonexpandable, stainless steel design. Circulation 1993; 88:2086-96. $\underline{\text { CrossRef }}$

15. Stefanini GG, Holmes DR Jr. Drug-eluting coronaryartery stents. N Engl J Med 2013;368:254-65. CrossRef

16. Stone GW, Ellis SG, Cox DA, et al. A polymer-based, paclitaxel-eluting stent in patients with coronary artery disease. N Engl J Med 2004;350:221-31. $\underline{\text { CrossRef }}$

17. Morice MC, Serruys PW, Sousa JE, et al. A randomized comparison of a sirolimus-eluting stent with a standard stent for coronary revascularization. N Engl J Med 2002;346:1773-80. $\underline{\text { CrossRef }}$
18. Stettler C, Wandel S, Allemann S, et al. Outcomes associated with drug-eluting and bare-metal stents: a collaborative network meta-analysis. Lancet 2007; 370:937-48. $\underline{\text { CrossRef }}$

19. Airoldi F, Colombo A, Morici N, et al. Incidence and predictors of drug-eluting stent thrombosis during and after discontinuation of thienopyridine treatment. Circulation 2007;116:745-54. CrossRef

20. Otsuka F, Vorpahl M, Nakano M, et al. Pathology of second-generation everolimus-eluting stents versus first-generation sirolimus- and paclitaxel-eluting stents in humans. Circulation 2014;129:211-23. CrossRef

21. Sakamoto A, Jinnouchi H, Torii S, Virmani R, Finn AV. Understanding the impact of stent and scaffold material and strut design on coronary artery thrombosis from the basic and clinical points of view. Bioengineering (Basel) 2018;5:E71. $\underline{\text { CrossRef }}$

22. Kedhi E, Stone GW, Kereiakes DJ, et al. Stent thrombosis: insights on outcomes, predictors and impact of dual antiplatelet therapy interruption from the SPIRIT II, SPIRIT III, SPIRIT IV and COMPARE trials. EuroIntervention 2012;8:599-606. $\underline{\text { CrossRef }}$

23. Navarese EP, Tandjung K, Claessen B, et al. Safety and efficacy outcomes of first and second generation durable polymer drug eluting stents and biodegradable polymer biolimus eluting stents in clinical practice: comprehensive network meta-analysis. BMJ 2013;347:f6530. $\underline{\text { CrossRef }}$

24. Bønaa KH, Mannsverk J, Wiseth R, et al. Drugeluting or bare-metal stents for coronary artery disease. N Engl J Med 2016;375:1242-52. $\underline{\text { CrossRef }}$

25. Guagliumi G, Sirbu V, Musumeci G, et al. Examination of the in vivo mechanisms of late drug-eluting stent thrombosis. JACC Cardiovasc Interv 2012;5:1220. $\underline{\text { CrossRef }}$

26. Kuriyama N, Kobayashi Y, Nakama T, et al. Late restenosis following sirolimus-eluting stent implantation. JACC Cardiovasc Interv 2011;4:123-8. CrossRef

27. Otsuka F, Byrne RA, Yahagi K, et al. Neoatherosclerosis: overview of histopathologic findings and implications for intravascular imaging assessment. Eur Heart J 2015;36:2147-59. CrossRef

28. Hopkins C, Sweeney CA, O'Connor C, McHugh PE, McGarry JP. Webbing and delamination of drug eluting stent coatings. Ann Biomed Eng 2016;44:419-31. $\underline{\text { CrossRef }}$

29. Worthley SG, Abizaid A, Kirtane AJ, et al. First-inhuman evaluation of a novel polymer-free drug-filled stent: angiographic, IVUS, OCT, and clinical outcomes from the RevElution study. JACC Cardiovasc Interv 2017;10:147-56. $\underline{\text { CrossRef }}$ 
30. Garot P, Morice MC, Tresukosol D, et al. 2-year outcomes of high bleeding risk patients after polymerfree drug-coated stents. J Am Coll Cardiol 2017;69: 162-71. CrossRef

31. Verdoia M, Kedhi E, Suryapranata H, Galasso G, Dudek D, De Luca G. Polymer free vs polymer-coated drug-eluting stents for the treatment of coronary artery disease: a meta-analysis of 16 randomized trials. Cardiovasc Revasc Med 2019 Oct 23; pii S1553-8389(19)30670-0. [Epub ahead of print] CrossRef

32. Byrne RA, Kastrati A, Kufner S, et al. Randomized, non-inferiority trial of three limus agent-eluting stents with different polymer coatings: the Intracoronary Stenting and Angiographic Results: Test Efficacy of 3 Limus-Eluting Stents (ISAR-TEST-4) Trial. Eur Heart J 2009;30:2441-9. CrossRef

33. Windecker S, Serruys PW, Wandel S, et al. Biolimuseluting stent with biodegradable polymer versus sirolimus-eluting stent with durable polymer for coronary revascularization (LEADERS): a randomised non-inferiority trial. Lancet 2008;372:1163-73 CrossRef

34. Palmerini T, Biondi-Zoccai G, Della Riva D, et al. Clinical outcomes with bioabsorbable polymer- versus durable polymer-based drug-eluting and baremetal stents: evidence from a comprehensive network meta-analysis. J Am Coll Cardiol 2014;63:299-307. CrossRef

35. El-Hayek G, Bangalore S, Casso Dominguez A, et al. Meta-analysis of randomized clinical trials comparing biodegradable polymer drug-eluting stent to secondgeneration durable polymer drug-eluting stents. JACC Cardiovasc Interv 2017;10:462-73. CrossRef

36. Kandzari DE, Mauri L, Koolen JJ, et al. Ultrathin, bioresorbable polymer sirolimus-eluting stents versus thin, durable polymer everolimus-eluting stents in patients undergoing coronary revascularisation (BIOFLOW V): a randomised trial. Lancet 2017;390: 1843-52. $\underline{\text { CrossRef }}$

37. Roguin A, Kandzari DE, Marcusohn E, et al. Subgroup analysis comparing ultrathin, bioresorbable polymer sirolimus-eluting stents versus thin, durable polymer everolimus-eluting stents in acute coronary syndrome patients. Circ Cardiovasc Interv 2018;11: eo07331. $\underline{\text { CrossRef }}$

38. Yamaji K, Zanchin T, Zanchin C, et al. Unselected use of ultrathin strut biodegradable polymer sirolimuseluting stent versus durable polymer everolimuseluting stent for coronary revascularization. Circ Cardiovasc Interv 2018;11:e006741. $\underline{\text { CrossRef }}$

39. Omar WA, Kumbhani DJ. The current literature on bioabsorbable stents: a review. Curr Atheroscler Rep 2019;21:54-60. $\underline{\text { CrossRef }}$
40. Ellis SG, Kereiakes DJ, Metzger DC, et al. Everolimuseluting bioresorbable scaffolds for coronary artery disease. N Engl J Med 2015;373:1905-15. CrossRef

41. Kereiakes DJ, Ellis SG, Metzger C, et al. 3-Year clinical outcomes with everolimus-eluting bioresorbable coronary scaffolds: the ABSORB III trial. J Am Coll Cardiol 2017;70:2852-62. $\underline{\text { CrossRef }}$

42. Ykrzykowska JJ, Kraak RP, Hofma SH, et al. Bioresorbable scaffolds versus metallic stents in routine PCI. N Engl J Med 2017;376:2319-28. CrossRef

43. de la Torre Hernandez JM, Gonzalo N, Otaegui I, et al. Device specificity of vascular healing following implantation of bioresorbable vascular scaffolds and bioabsorbable polymer metallic drug-eluting stents in human coronary arteries: the ESTROFA OCT BVS vs. BP-DES study. EuroIntervention 2018;14:e1295303. CrossRef

44. Kereiakes DJ, Ellis SG, Metzger DC, et al. Clinical outcomes before and after complete everolimuseluting bioresorbable scaffold resorption: five-year follow-up from the ABSORB III trial. Circulation 2019;140:1895-903. CrossRef

45. King SB 3rd, Gogas BD. Can the vanishing stent reappear?: Fix the technique, or fix the device? J Am Coll Cardiol 2017;70:2875-7. $\underline{\text { CrossRef }}$

46. Neumann FJ, Sousa-Uva M, Ahlsson A, et al. 2018 ESC/EACTS guidelines on myocardial revascularization. Eur Heart J 2019;40:87-165. CrossRef

47. Fu J, Su Y, Qin YX, Zheng Y, Wang Y, Zhu D. Evolution of metallic cardiovascular stent materials: a comparative study among stainless steel, magnesium and zinc. Biomaterials 2020;230:119641. $\underline{\text { CrossRef }}$

48. Hideo-Kajita A, Garcia-Garcia HM, Haude M, et al. First report of edge vascular response at 12 months of magmaris, a second-generation drug-eluting resorbable magnesium scaffold, assessed by grayscale intravascular ultrasound, virtual histology, and optical coherence tomography. A Biosolve-II trial sub-study. Cardiovasc Revasc Med 2019;20:392-8. CrossRef

49. Haude $\mathrm{M}$, Ince $\mathrm{H}$, Kische $\mathrm{S}$, et al. Safety and clinical performance of a drug eluting absorbable metal scaffold in the treatment of subjects with de novo lesions in native coronary arteries: pooled 12-month outcomes of BIOSOLVE-II and BIOSOLVE-III. Catheter Cardiovasc Interv 2018;92:E502-11.

50. Gao L, Chen YD. Application of drug-coated balloon in coronary artery intervention: challenges and opportunities. J Geriatr Cardiol 2016;13:906-13. CrossRef 